\title{
The Environmental Photochemistry of Oxide Surfaces and the Nature of Frozen Salt Solutions: A New in Situ XPS Approach
}

\author{
Fabrizio Orlando $^{1}$ - Astrid Waldner ${ }^{1}$ - Thorsten Bartels-Rausch ${ }^{1} \cdot$ Mario Birrer $^{1}$ • \\ Shunsuke Kato ${ }^{1,6} \cdot$ Ming-Tao Lee ${ }^{1}$ - Christian Proff ${ }^{2,3}$ - Thomas Huthwelker ${ }^{4}$. \\ Armin Kleibert $^{4} \cdot$ Jeroen van Bokhoven $^{2,5} \cdot$ Markus Ammann ${ }^{1}$
}

Published online: 11 January 2016

(C) The Author(s) 2016. This article is published with open access at Springerlink.com

\begin{abstract}
Recent years have witnessed fast advancements in near ambient pressure X-ray photoelectron (NAPP) spectroscopy, which is emerging as a powerful tool for the investigation of surfaces in presence of vapors and liquids. In this paper we present a new chamber for the investigation of solid/vapor interfaces relevant to environmental and atmospheric chemistry that fits to the NAPP endstation at the Swiss Light Source. The new chamber allows for performing X-ray photoelectron spectroscopy (XPS) and electron yield near-edge X-ray absorption fine structure spectroscopy (NEXAFS) using soft, tender and hard X-ray in vacuum and in near-ambient pressures up to 20 mbar at environmentally relevant conditions of temperature and relative humidity. In addition, the flow tube design of the chamber enables the dosing of sticky reactive gases with short pressure equilibration time. The accessible photoelectron kinetic energy ranges from 2 to $7000 \mathrm{eV}$. This range allows the determination of surface and bulk
\end{abstract}

Markus Ammann

markus.ammann@psi.ch

1 Laboratory of Radiochemistry and Environmental Chemistry, Paul Scherrer Institut, 5232 Villigen PSI, Switzerland

2 Laboratory for Catalysis and Sustainable Chemistry, Paul Scherrer Institut, 5232 Villigen PSI, Switzerland

3 Bioenergy and Catalysis Laboratory, Paul Scherrer Institut, 5232 Villigen PSI, Switzerland

4 Swiss Light Source, Paul Scherrer Institut, 5232 Villigen PSI, Switzerland

5 Institute for Chemical and Bioengineering, ETH Zurich, 8093 Zurich, Switzerland

6 Present Address: Laboratory of Materials for Renewable Energy, École polytechnique fédérale de Lausanne (EPFL), 1951 Sion, Switzerland electronic properties of ice and other environmental materials, such as metal oxides and frozen solutions, which are relevant to understanding atmospheric chemistry. The design of this instrument and first results on systems of great interest to the environmental and atmospheric chemistry community are presented. In particular, nearambient pressure XPS and NEXAFS, coupled to a UV-laser setup, were used to study the adsorption of water on a $\mathrm{TiO}_{2}$ powder sample. The results are in line with previously proposed adsorption models of water on $\mathrm{TiO}_{2}$, and, furthermore, indicate that the concentration of water molecules tends to increase upon UV irradiation. In a second example we illustrate how NEXAFS spectroscopy measurements at the chlorine K-edge can provide new insight on the structures of eutectic and sub-eutectic frozen $\mathrm{NaCl}$ solutions at high and low relative humidity, respectively, indicating the formation of solution and solid $\mathrm{NaCl}$ phases, respectively. Finally, we demonstrate the assets of this new chamber for the dosing of sticky acidic gases and, in particular, for the investigation of formic acid uptake on ice surfaces.

Keywords Metal oxides - Ice $\cdot$ Halogens $\cdot$ X-ray photoelectron spectroscopy (XPS) · Near-edge X-ray absorption fine structure (NEXAFS) · Near ambient pressure photoemission (NAPP)

\section{Introduction}

Since its development between 1950 and 1960 by K. Siegbahn, X-ray photoelectron spectroscopy (XPS) has been successfully employed in a number of scientific fields, including heterogeneous catalysis, materials science or semiconductor technology, just to name a few. However, 
the pressure limitations imposed by the electron energy analyzer, which must be kept under high vacuum conditions, and by the short inelastic mean free path (IMFP) of the photoelectrons at elevated pressure has traditionally restricted the application of this technique mainly to solid/vacuum interfaces, with some pioneering exceptions [1-3]. This also explains why, despite XPS being one of the most powerful and widely used surface science characterization tools, the potential of this technique has not been fully exploited for practical systems and samples in operating conditions. A crucial step forward in this direction has been made via the development of differentiallypumped electrostatic lenses [4], which has greatly improved the transmission of photoelectrons through the analyzer, thus allowing for XPS measurements performed close to ambient pressure, better known as near ambient pressure photoelectron spectroscopy (NAPP). The fast development of NAPP in the last years [5-10] has benefited from the advent of 3rd generation synchrotron radiation sources, with the brilliant and focused beams of which electron scattering losses in the gas phase could be counteracted, resulting in NAPP measurements with an improved signal-to-noise ratio.

The possibility to bridge, at least partially, the so-called "pressure-gap" between ultra-high vacuum (UHV) and catalytic operating conditions [11] has extended the range of applicability of XPS characterization to solid/liquid and solid/vapor interfaces. This has opened the door to a broader scientific audience, especially in electrochemistry [12], environmental chemistry [13] and heterogeneous catalysis [10]. In particular, environmental science is one of the disciplines that has seen some of the early applications of NAPP [14] and still offers tremendous further opportunities. Indeed, not only chemical reactions in the atmosphere take place under humid conditions, but water vapor is frequently one of the main reactants, e.g., in hydrolysis reactions. Water is present on solid surfaces at ambient conditions, forming several molecular layers at room temperature $[15,16]$. Water in the form of ice is also a predominant material in some parts of the Earth, as snowpack or sea-ice, and in the atmosphere, in the form of ice particles. Chemical reactions at air-ice interfaces of snow or sea-ice, where the exchange of major and trace gases occurs, drive large-scale environmental effects such as ozone depletion events in Polar areas, and modify the cycling of halogen gases, and of nitrogen oxides on a global scale [17-23]. These examples show how heterogeneous chemistry affects the oxidative capacity of the atmosphere. The latter can be affected also by photochemical processes, such as the photochemistry of nitrogen oxides on mineral oxide particles contained in atmospheric mineral dust plumes uplifted from arid areas, which represents another important playground for atmospheric chemistry and climate science. So far, only few experiments have attempted to probe surface species on, e.g., ice [24] or mineral oxides [25, 26] under atmospheric conditions. Indeed, the high water vapor pressure at environmentally relevant temperature (0.01-1 mbar) makes it difficult to use surface sensitive probes, thus pointing out the importance and potential of near ambient pressure XPS for environmental research.

Here we present a new chamber for the NAPP endstation [27] at the Swiss Light Source (SLS) designed for in situ XPS and electron yield near edge X-ray absorption fine structure spectroscopy (NEXAFS) at solid/vapor interfaces under environmentally relevant conditions of temperature and pressure. Compared to many NAPP systems, which consist of (relatively large) UHV chambers that are filled with vapors or gases up to the desired pressure in a nearly static regime, our chamber is designed as a compact flow tube cell surrounded by an external UHV environment. This layout enables to quickly shift between measurements at near ambient pressure and UHV conditions while at the same time reducing the exposed volume and surface area of the cell. In addition, it features a direct access from a gas dosing system down to the sample to allow admission of sticky gases. Following the concept originally conceived for the NAPP endstation of custom designed chambers dedicated to specific applications, the new chamber for solid samples can be exchanged with that dedicated to liquid microjet experiments described in Ref. [27]. The NAPP endstation, which covers an electron kinetic energy range of $2-7000 \mathrm{eV}$, can be operated at the SIM [28] and PHOENIX [29] beamlines at the Swiss Light Source (SLS) at the Paul Scherrer Institute (PSI) for experiments with soft and hard X-rays, respectively. The accessible photon energy range can be further extended by connecting a $\mathrm{He}$ discharge lamp, allowing for off-line ultraviolet photoelectron spectroscopy (UPS) measurements.

\subsection{Near Ambient Photoelectron Spectroscopy at SLS}

Figure 1a shows a picture of the NAPP endstation with the new chamber for the investigation of solid/vapor interfaces. The schematic drawing of the whole assembly reported in Fig. 1b illustrates the modular design of the NAPP endstation, which can accommodate either the chamber for solid samples (1) or the liquid microjet module [27] and enables flexible switching between these two operation modes. The endstation is equipped with a Scienta R4000 HiPP-2 electron energy analyzer (200 $\mathrm{mm}$ mean radius) with variable entrance slit, coupled to a multi-channel plate (MCP) detector and a charge-coupled device (CCD) camera (2); the performance and design of this instrument are 


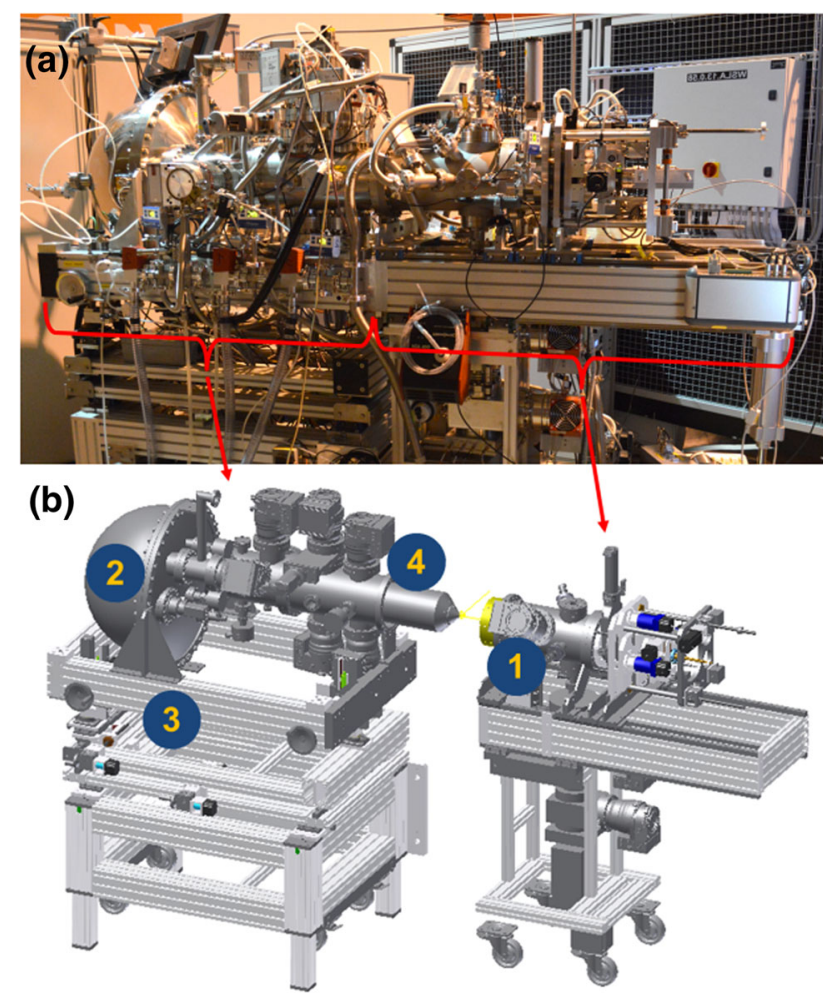

Fig. 1 a Picture of the new chamber for solid samples connected to the NAPP endstation. The endstation is mounted on a moveable frame to be attached to the SIM or to the PHOENIX beamline at PSI/SLS. b Schematic layout of the NAPP endstation with the R4000 HiPP-2 electron energy analyzer (left hand side) together with the new chamber (right hand side). See text for details

similar to those described in Ref. [7, 30]. The analyzer is mounted on a mobile frame allowing for movement in the $\mathrm{x}, \mathrm{y}$ plane and in the $\mathrm{z}$ direction (3). In addition, the analyzer can rotate along the yaw, pitch and roll axes for fine alignment. All the movements are realized via commercially available stepper motors, with a resolution of $10 \mu \mathrm{m}$ and $0.01 \mathrm{mrad}$ for linear and rotational movements, respectively. These features ensure the flexibility required to operate the endstation at both SIM and PHOENIX beamlines at the SLS. The differential pumping on the electron lens and pre-lens (4), each fitted with three elements, allows XPS and electron yield NEXAFS measurements up to 20 mbar within an electron kinetic energy range from 2 to $7000 \mathrm{eV}$.

Shown in Fig. 2a is the schematic of the in situ cell together with the flow tube, which is $3 \mathrm{~cm}$ in diameter and has a length of $15 \mathrm{~cm}$. In order to minimize the effect of external magnetic fields, a $\mu$-metal shield covers the flow tube, the in situ cell and part of the sample manipulator. The flow tube and the in situ cell, which is pushed directly onto the analyzer nozzle, are surrounded by an external UHV environment (Fig. 2b), and the two are connected through a bypass: only the in situ cell is filled with vapors or gases, with the ultimate pressure limit depending on the diameter of the analyzer entrance cone (see below). After opening the bypass valve, a pressure drop from $\sim 1 \mathrm{mbar}^{\mathrm{O}} \mathrm{O}_{2}$ to below $5 \times 10^{-7}$ mbar in the sample region is achieved usually within less than $30 \mathrm{~min}$. The possibility to quickly vary the pressure at the sample allows performing UHV and high pressure measurements one after the other in the same analysis cell. Compared to a standard XPS setup, where the dosing of reactive gases is very difficult due to their interaction with the large surface of the analysis chamber and any other part associated with it (bellows, manipulators, etc.), our flow tube approach minimizes the internal surface and permits dosing sticky gases with reduced wall effects. This is possible thanks to the minimized surface area of only $140 \mathrm{~cm}^{2}$ of the flow tube section between the exit of the gas dosing line (described below) and the sample. This feature distinguishes our chamber from all other setups dedicated to near ambient pressure XPS, even from those featuring smaller reaction chambers but longer gas admission lines through manipulator arms [8, 31]. At the present stage, the in situ cell and the flow tube are made of aluminum, but an upgrade to titanium is in order.

As shown in Fig. 2a, the X-ray beam enters the analysis chamber through a $1.5 \mathrm{~mm} \times 1.5 \mathrm{~mm} \times 100 \mathrm{~nm}$ thick $\mathrm{Si}_{3} \mathrm{~N}_{4}$ window, which ensures vacuum protection to the beamline when working at high pressures (mbar range). Furthermore, physical separation between chamber and beamline also allows for using particularly corrosive gases. The impinging beam, the sample surface normal, and the analyzer axis lie in the same horizontal plane. The photon incident $\left(\theta_{p h}\right)$ and the electron emission $\left(\theta_{e}\right)$ angles are $60^{\circ}$ and $30^{\circ}$ from the sample surface normal, respectively, with the angle between the photon beam and the analyzer fixed at $90^{\circ}$ (see the schematic illustration in Fig. 2a). The angle between the linear polarization vector and the electron emission axis can be varied between $0^{\circ}$ and $90^{\circ}$ both at SIM and PHOENIX beamlines. The distance between the $\mathrm{Si}_{3} \mathrm{~N}_{4}$ window and the sample is $15 \mathrm{~mm}$. The in situ cell is equipped with two viewports (Fig. 2b) on which a highresolution endoscope and a wide-angle camera can be mounted. This allows for looking at the sample for alignment purposes, and for monitoring whether or not its surface changes appearance with time during the experiment.

The top part of the flow tube holds the dosing line. Gases and vapors, such as water, are mixed together before entering the flow tube. While gas flow is commonly controlled via leak valves, here, in addition, the vapor flow from volatile liquids is regulated by controlling the temperature of the liquid itself (and hence its vapor pressure) with a Peltier cell. More precisely, the flow rate is determined by the pressure difference along a capillary tube: one end is connected to the temperature-controlled reservoir of the liquid, while the other end is connected to the flow tube of the 
Fig. 2 NAPP in situ cell setup. a Section view of the in situ cell together with the flow tube: the sample is in measurement position and the inlet and outlet tubes are shown together with the entrance cone of the electron spectrometer. A schematic of the measurement geometry is reported on the left side (see text for details). b Picture of a view into the in situ cell, the flow tube and surrounding UHV chamber as seen from the electron analyzer. c Liquid nitrogen cooled and $\mathbf{d}$ IR-heated manipulators
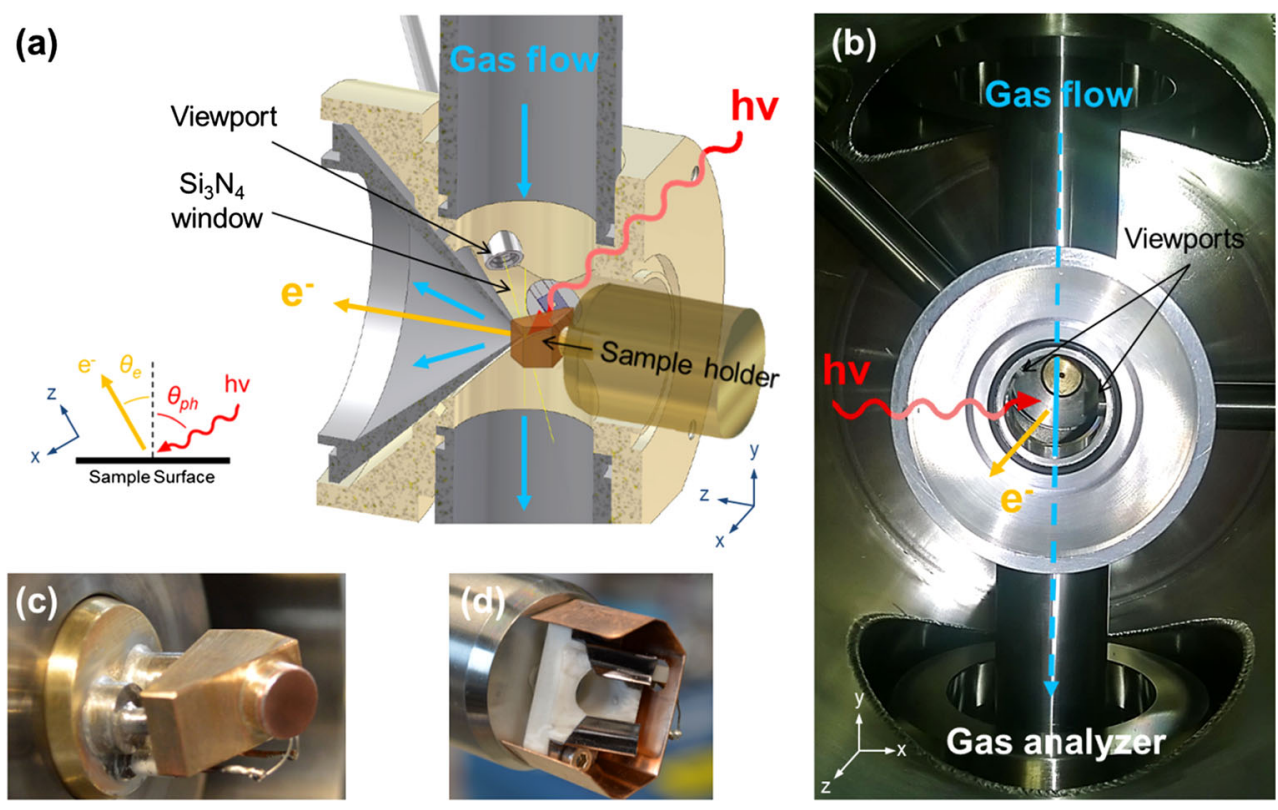

analysis cell. The reservoirs hold the liquid and its vapor, and are made of glass to minimize chemical reactions with, e.g., acidic liquids, or leaching promoted by these. The capillaries that transport the vapors to the flow tube with a diameter of $0.3-2.0 \mathrm{~mm}$ are made of stainless steel, while those with a diameter of $0.1-0.2 \mathrm{~mm}$ to dose acidic traces or other sticky gases are made of fused silica. A typical length of the capillaries is $1 \mathrm{~m}$. With such a dosing system attached to the flow tube, the surface area that the trace gas and vapors are exposed to increases to almost $600 \mathrm{~cm}^{2}$, with a total volume of about $550 \mathrm{~cm}^{3}$. Figure $3 \mathrm{a}$ highlights the flexibility of this approach for water and formic acid ( $\mathrm{HCOOH})$ dosing. For instance, by changing the water vapor pressure in the reservoir between 1 mbar and 15 mbar, reflecting temperatures of ice or water from 253 to $286 \mathrm{~K}$, the pressure in the flow tube cell can be varied between 0.02 mbar and 1.4 mbar (blue dots). Partial pressures between $10^{-3}$ mbar and $10^{-1}$ mbar in the flow tube are realized with vapor pressures of formic acid in the dosing reservoir ranging from 8 to 50 mbar (pink dots). Figure 3a further illustrates the high reproducibility of this dosing approach, as the individual data come from independent measurements. Figure $3 \mathrm{~b}$ shows a selection of the formic acid dosing data. At time of $0 \mathrm{~h}$ the valve separating the formic acid reservoir at $265 \mathrm{~K}$ and the dosing capillary connecting with the analysis cell was opened. Then, in intervals of 30 to $60 \mathrm{~min}$, the temperature of the formic acid in the reservoir was increased stepwise from 265 to $281 \mathrm{~K}$ to raise the vapor pressure at the
Fig. 3 a Partial pressures of water (blue dots) and formic acid (pink dots) measured in the in situ cell as a function of the pressure measured in the reservoirs containing the corresponding liquid or frozen solid, respectively. b Evolution of the formic acid pressure in the reservoir (orange line) and of the partial pressure of formic acid in the analysis cell (pink line) with time
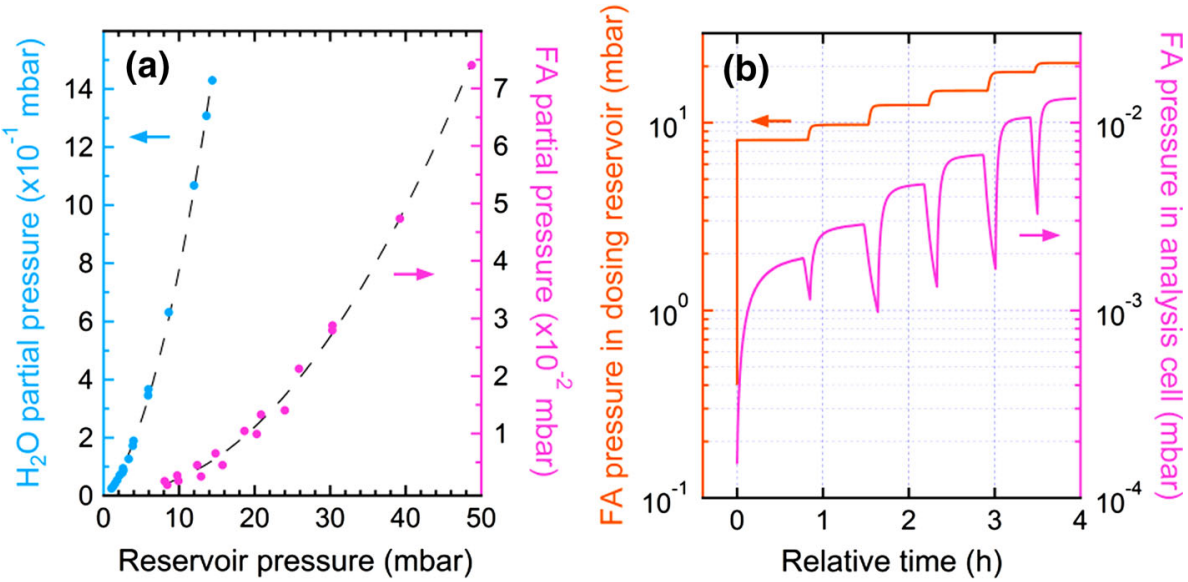
inlet of the capillary (orange line). Whenever the temperature of the reservoir was changed, the valve connecting the reservoir and the capillary (the latter connected to the analysis cell) was closed and reopened once the pressure in the reservoir had stabilized. This explains the pressure drops in between the stepwise increases of the formic acid partial pressure in Fig. 3b. Generally, the data set illustrates the fast response time of the pressure in the reservoir to changes of the temperature and the stable formic acid pressure in the reservoir over hours. Even more, the pressure in the analysis cell shows a fast response of $\sim 10 \mathrm{~min}$ to reach $\sim 90 \%$ of the final pressure; the last $10 \%$ steadily and slightly increase over timescales of about an hour. This is a significant improvement in the response time compared to the standard NAPP setups, where response times of several hours were reported at comparable partial pressures of acetic acid [32]. For these measurements formic acid (98 \%, Fluka 56302, stored at $252 \mathrm{~K}$ ) was used and cleaned by freeze-pump-thaw cycles immediately before the dosing experiment.

A molecular beam sampling mass spectrometer (Hiden HPR-60) is mounted directly at the lower exit of the flow tube for quantitative analysis of the reactive gas species. Additionally, a quadrupole mass spectrometer is mounted at the second stage of the analyzer pre-lenses. The high pressure in the inner chamber is monitored by baratron capacitance manometers (MKS 626), while in all the other vacuum sections the pressures are probed by full range gauge sensors (Pfeiffer HPT-100). The pressure in the in situ cell is given by the inlet gas flow via the capillaries or the leak valve and by the gas flow being pumped by the electron analyzer and the Hiden mass spectrometer. The outlet flow depends on the diameters of both mass spectrometer and electron energy analyzer orifices. The mass spectrometer is usually operated with an orifice of $0.4 \mathrm{~mm}$ diameter, while the electron analyzer either with 0.3 or $0.5 \mathrm{~mm}$. A back-of-theenvelope calculation of the viscous and molecular flows via either of the orifices indicates that the in situ cell is typically operated at total flows between $20 \mathrm{ml} / \mathrm{min}$ at $10 \mathrm{mbar}$ and $0.1 \mathrm{ml} / \mathrm{min}$ at $0.1 \mathrm{mbar}$ total pressure in the in situ cell (volumetric flows at standard temperature and pressure (STP)). These rough calculations have been confirmed by measurements of the flows using mass flow controllers.

Cooling and heating of samples are challenging task in a NAPP experiment. Indeed, when working with condensable gases, the manipulator sample surface has to be coldest point in the chamber, otherwise the gas will condense elsewhere. Also, traditional heating filaments, such as tungsten or platinum wires, cannot be used in oxidizing environments because they would either burn away or catalyze undesired reactions. To perform experiments with condensable gases a sample holder has been developed that is equipped with a liquid nitrogen cryostat (Fig. 2c). This sample holder allows performing experiments at temperatures down to $160 \mathrm{~K}$ and, thus, to reach high relative humidity (RH) up to the water condensation point (100\% RH) at still reasonably low water partial pressure. This permits to address surface chemical composition at atmospherically relevant conditions. Thanks to the reduced temperature fluctuations below $0.2 \mathrm{~K}$, ice samples can be grown on the cooled surface of this manipulator, as illustrated in the next section. In addition, this manipulator can also heat samples up to about $373 \mathrm{~K}$ by annealing the copper radiator serpentine with a heating plate. A second sample holder, equipped with an IR laser diode (Laser Components, $915 \mathrm{~nm}, 25 \mathrm{~W}$ ), allows control of the sample temperature between 293 and 1270 K (Fig. 2d). The laser diode is connected to an optical fiber, which directs the IR beam on the backside of the sample mounting plate. This sample holder offers also a rotational movement along the $\mathrm{z}$ axis. As future prospective, this possibility to heat the sample will allow NAPP investigation of reactions on catalytic surfaces at elevated temperatures, which will further extend the versatility of this endstation.

Sample manipulation is another critical part of a NAPP system, as several technical issues arise when the sample has to be precisely positioned in a near ambient pressure environment that, at the same time, is sealed against UHV. Our new chamber features a load lock system allowing for a quick sample entry from ambient air to vacuum: the sample is first mounted on the manipulator and the whole stage is then connected to the gate valve. After evacuation of this volume, the gate valve opens and the sample is introduced in the flow-cell while the manipulator rod connects to the opening of the flow tube, thus assuring vacuum-tight sealing. The sample manipulator and its link to the translation stages are designed such that seals only exist between the analysis cell and the surrounding UHV volume on the one hand, and between the air side and the UHV chamber on the other hand. The sample load procedure is fully automated and requires short time, thus allowing for fast sample exchange. Sample positioning with a precision of $\pm 5 \mu \mathrm{m}$ along $\mathrm{x}, \mathrm{y}$, and $\mathrm{z}$ axes is achieved with linear stage drives controlled via a LabVIEW based software. This enables a precise control of the sample position, which is a critical parameter for high pressure measurements. Indeed, the effective pressure at the sample surface is reduced due to the perturbation of the entrance cone aperture. It is calculated that at a distance of $2 R$ ( $R$ being the radius of the cone aperture), the local pressure is about $95 \%$ of the total pressure in the chamber $[6,16]$. Remarkably, even small variations of the pressure field can lead to sizeable effects. For instance, we observed preferential evaporation of the ice surface close to the entrance cone at working distances below $2 \mathrm{R}$, as previously reported in Ref. [16], most probably due to a combination of local pressure reduction and radiative heating of the ice 
surface by the aperture cone. To avoid such issues during the investigation of ice samples, our analyzer can be fitted with customized entrance cones realized in such a way that the working distance, i.e., the distance between the orifice and the focus of the analyzer in the center of the analysis cell where the sample is positioned, corresponds to $4 R$. Moreover, thanks to the high quality of the lens focusing system and the possibility to accurately align the chamber with respect to the photon beam, the working distance can be further optimized, thus permitting a precise tuning of the measurement geometry.

Figure 4 shows the layout of the vacuum system, which is almost identical to that shown in Ref. [27], except for the different experimental chamber. All the turbo pumps are from Pfeiffer (HiPace $300 \mathrm{l} / \mathrm{s}$ ), while the root pumps of the pre-pumping stages are from Adixen $(600 \mathrm{l} / \mathrm{s})$. When the bypass is closed for high pressure measurements, the flow tube chamber is pumped through the orifices of the electron energy analyzer and mass spectrometer.

Similar to a setup we previously tested at the beamline 9.3.2 at ALS [25], a UV laser diode (Oxxius, $375 \mathrm{~nm}, 15$ $\mathrm{mW}$ ) is mounted on the viewport of the hemispherical electron energy analyzer and aligned to the measurement spot on the sample through the analyzer aperture by an adjustable mount. This experimental configuration allows the in situ investigation of photoactive materials under atmospherically relevant conditions and light while, compared to other setups [26], reducing the extent of gas phase photochemistry induced by UV irradiation.

\section{Proof-of-Principle Measurements}

In this section we provide selected examples that demonstrate the system capabilities. More precisely, we report on the preliminary study of three scientific cases of major impact in environmental and atmospheric chemistry, such as photochemistry of titania $\left(\mathrm{TiO}_{2}\right)$ nanoparticles, interaction of trace gases with ice, and study of frozen $\mathrm{NaCl}$-water mixtures.

\subsection{Photocatalysis on $\mathrm{TiO}_{2}$}

Photocatalysis on $\mathrm{TiO}_{2}$ is a major topic of research due to its straightforward implications for depolluting appliances [33, 34] and atmospheric chemistry [35]. For instance, $\mathrm{TiO}_{2}$ is a component of natural mineral dust that represents an important reactive aerosol in the atmosphere affecting the ozone budget and the climate [36]. In this context, adsorption of water and hydroxylation of the surface, which are key aspects to understand $\mathrm{TiO}_{2}$ photocatalysis in the environment, offer still major open questions. Earlier near ambient pressure XPS studies have provided important insight into the nucleation of water on this surface [37, 38]. In a recent study we have quantified the effect of humidity on ozone-induced band bending on the $\mathrm{TiO}_{2}(110)$ surface [39], and found interesting changes in the partial electron yield oxygen K-edge absorption spectra indicative of changes in the hydrogen bonding structure in multilayers of water. Moreover, we have lately shown how the downward band bending induced by UV light [40] is likely to change the water adsorption properties on $\mathrm{TiO}_{2}(110)$ [25]. With the aim of improving the understanding of these issues, we have conducted first experiments using the NAPP set-up for a water adsorption experiment over a $\mathrm{TiO}_{2}$ powder sample (Degussa P25) under UV-irradiation and relevant atmospheric conditions of humidity.

The $\mathrm{TiO}_{2}$ samples were prepared according to the following procedure. A homogeneous solution of $\mathrm{TiO}_{2}$ powder and ethanol was prepared and deposited on the goldcoated surface of the cooled manipulator. The sample was
Fig. 4 Schematic of the vacuum system: the typical pressures are measured with the $0.5 \mathrm{~mm}$ aperture cone (adapted from [27])

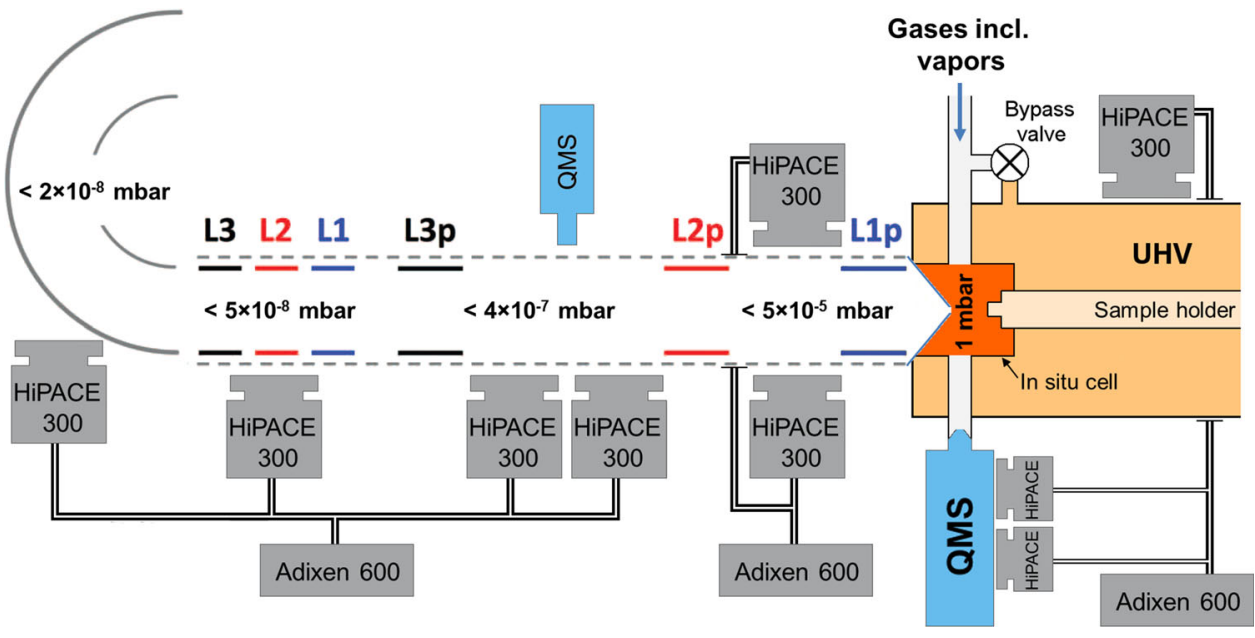


then dried to evaporate the ethanol and loaded into the analysis cell. The $\mathrm{O} 1 \mathrm{~s}$ core level spectra shown below were measured at a photon energy of $730 \mathrm{eV}$ and aligned with respect to the Fermi level, measured on the goldcoated surface of the manipulator in the same experimental conditions. The NEXAFS spectra were measured in Auger yield mode and are normalized to the beam intensity, recorded with a photodiode mounted instead of the sample before (and after) the experiments were performed. The $\mathrm{O}$ K-edge NEXAFS spectra were measured at the "magic angle" of $54.7^{\circ}$ between the (linear) polarization of the incident X-ray and the $\mathbf{k}$ vector of the electrons, using an electron kinetic energy window of $460-520 \mathrm{eV}$. These measurements were performed at the SIM beamline. The Ti K-edge NEXAFS measurements were performed at the PHOENIX beamline using a kinetic energy range of $3960-4020 \mathrm{eV}$. Oxygen was admitted to the chamber through a leak valve, while water was dosed using the capillary system described above.

Figure 5 shows the $\mathrm{O} 1 \mathrm{~s}$ core level measured (a) in vacuum and (b) in humid conditions (5\% RH) and 0.06 mbar partial pressure of $\mathrm{O}_{2}$. As illustrated by the evolution of the $\mathrm{O} 1 \mathrm{~s}$ core level region, several components

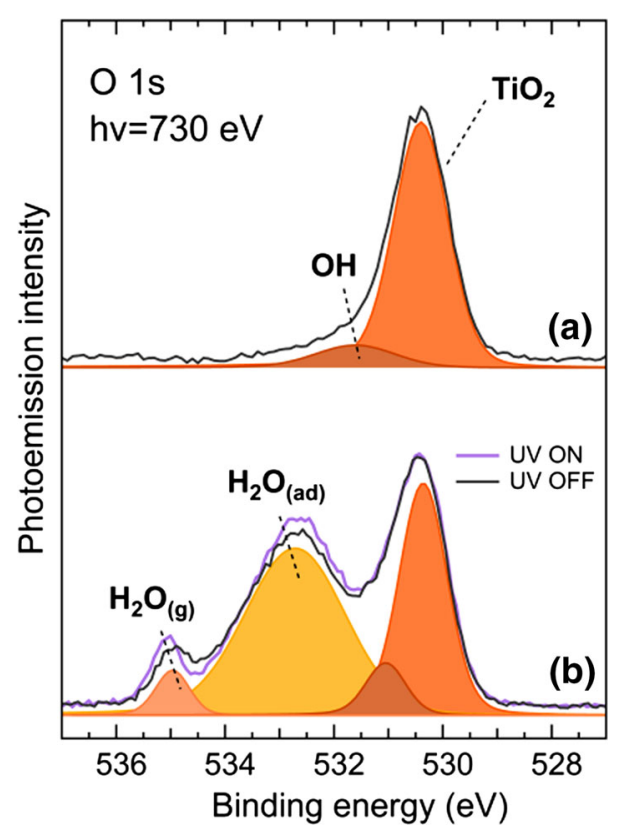

Fig. $5 \mathrm{O} 1 \mathrm{~s}$ photoemission spectra of the $\mathrm{TiO}_{2}$ powder sample measured $\mathbf{a}$ in vacuum and $\mathbf{b}$ at 0.06 mbar partial pressure of $\mathrm{O}_{2}$ at $5 \% \mathrm{RH}\left(0.36\right.$ mbar partial pressure of $\mathrm{H}_{2} \mathrm{O}$ at $\left.272 \mathrm{~K}\right)$ together with the fitting components, which are slightly shifted downward for display. Overlapped in $\mathbf{b}$ is also the spectrum measured during UV exposure. The binding energy scale for the $\mathrm{O} 1 \mathrm{~s}$ spectrum obtained on a clean surface in UHV conditions was constrained to the value of $530.4 \mathrm{eV}$ for the oxide $\mathrm{O} 1 \mathrm{~s}$ peak. All spectra are normalized to the oxide peak intensity after linear background subtraction. The measurements were performed at the SIM beamline appear upon water vapor exposure besides the main peak at $530.4 \mathrm{eV}$, which corresponds to oxygen in the $\mathrm{TiO}_{2}$ lattice. These components are associated to $\mathrm{OH}$ groups and molecular $\mathrm{H}_{2} \mathrm{O}$ at about 531.1 and $532.8 \mathrm{eV}$, respectively [37]. Oxygen-containing carbon contaminants, desorbing from the chamber walls once it is exposed to high pressure or originating from the water source, might also contribute to the spectral intensity in the $\mathrm{OH}$ binding energy range. However, no increase of the $\mathrm{C} 1 \mathrm{~s}$ intensity was observed during the experiment. The evolution of the spectral components as a function of RH is in line with previous experimental findings indicating a stepwise mechanism for water adsorption on $\mathrm{TiO}_{2}$. More precisely, water molecules dissociatively adsorb on the oxygen vacancies of $\mathrm{TiO}_{2}$ surfaces, leading to the formation of $\mathrm{OH}$ groups which act as nucleation centers for the adsorption of additional water molecules [37]. It can be observed that a small concentration of $\mathrm{OH}$ groups was found even before the admission of water into the chamber, most probably because the sample was not pretreated, e.g. annealed, before the measurements. The additional photoemission peak appearing at higher binding energy is associated with gas-phase water. It is noteworthy that the thickness of the water layer does not depend on the specific values of water vapor pressure and temperature, but only on their combination, i.e., on the $\mathrm{RH}$ value [6].

Figure 6 shows the comparison between O K-edge NEXAFS spectra measured in dark and under UV irradiation. The well-defined resonances $\mathrm{A} 1(531.3 \mathrm{eV})$ and $\mathrm{A} 2$ $(534.0 \mathrm{eV})$ correspond to excitations to $\mathrm{O} 2 \mathrm{p}-\mathrm{Ti} 3 \mathrm{~d}$ mixed states [41]. The $\mathrm{C} 1(540.0 \mathrm{eV})$ and $\mathrm{C} 2(546.0 \mathrm{eV})$ peaks arise from electron transfer to mixed states derived from $\mathrm{O}$ $2 \mathrm{p}$ and $\mathrm{Ti} 4$ sp states [41]. The adsorption of water on $\mathrm{TiO}_{2}$ causes an increase of the $\mathrm{C} 1$ and $\mathrm{C} 2$ resonances, as shown by the comparison between the NEXAFS spectra measured under dry (a) and humid (b) conditions. This is in accordance with the fact that these are the components most sensitive to oxygen-oxygen interactions, due to their prevailing oxygen $p$ character [41]. The observation that these components further increase upon UV irradiation indicates that the concentration of water molecules on the surface further tends to increase under UV light. This is in line with the previous experimental observation that UV light irradiation led to an enhanced concentration of hydroxyl groups [25]. Furthermore, the comparison between $\mathrm{O}$ K-edge spectra in Fig. 6a and $\mathrm{b}$ suggests that this photoinduced effect is sizeable only if a sufficiently large amount of $\mathrm{H}_{2} \mathrm{O}$ molecules is provided, i.e., the effect is almost negligible under dry conditions. The outlined scenario is supported by the $\mathrm{O} 1 \mathrm{~s}$ photoemission spectrum measured under humid conditions and during UV irradiation reported in Fig. 5b (purple spectrum), which shows an increase of the $\mathrm{H}_{2} \mathrm{O}_{(\text {ad })}$ component compared to the spectrum measured 


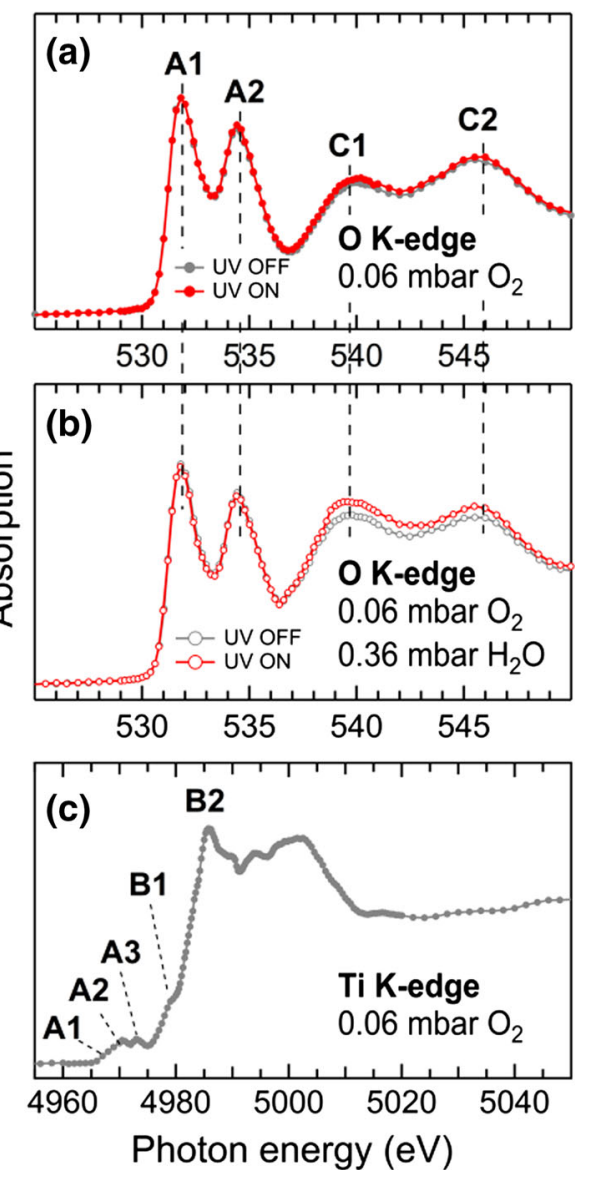

Fig. $6 \mathrm{O}$ K-edge NEXAFS spectra for a $\mathrm{TiO}_{2}$ powder sample in presence of a 0.06 mbar $\mathrm{O}_{2}$ and $\mathbf{b}$ with additional 0.36 mbar partial pressure of $\mathrm{H}_{2} \mathrm{O}$ in dark conditions (grey) and under UV light irradiation (red). c Ti K-edge NEXAFS spectrum for $\mathrm{TiO}_{2}$ powder sample at 0.06 mbar pressure of $\mathrm{O}_{2}$. The measurements in a and b were performed at the SIM beamline, while those in $\mathbf{c}$ at the PHOENIX beamline

under dark conditions (grey spectrum). It is worth noting that the contribution of the gas phase to the NEXAFS spectra reported in Fig. 6a, b is negligible because of the low water vapor partial pressure used. Moreover, the absorption peaks of the water gas phase [42] do not overlap with the $\mathrm{C} 1$ and $\mathrm{C} 2$ resonances of the $\mathrm{TiO}_{2}$ oxygen K-edge. Finally, Fig. 6c illustrates the titanium K-edge NEXAFS of the sample measured under 0.06 mbar oxygen pressure. This spectrum shows three typical pre-edge features A1, $\mathrm{A} 2$, and $\mathrm{A} 3$ that are associated to a mixing of $4 \mathrm{p}$ and $3 \mathrm{~d}$ titanium orbitals. The resonances B1 and B2, instead, are due excitations to Ti $4 \mathrm{sp}$ hybridized orbital with $\mathrm{O} 2 \mathrm{p}$ states [43]. It should be stressed that the capability to perform NEXAFS measurements with soft and hard X-rays brings about an enhanced depth selectivity. $\mathrm{TiO}_{2}$ is a good example in this regard, because the $\mathrm{O}$ and $\mathrm{Ti} \mathrm{K}$-edge NEXAFS provide complementary information due to the different IMFP of the corresponding Auger electrons.
Indeed, the electrons IMFP at 500 and $4000 \mathrm{eV}$ in $\mathrm{TiO}_{2}$, corresponding approximately to the kinetic energy of the $\mathrm{O}$ and Ti KLL Auger lines, is $\sim 13$ and $\sim 63 \AA$, respectively. This makes the $\mathrm{O}$ K-edge NEXAFS a surface probe compared to the more bulk sensitive Ti K-edge NEXAFS.

\subsection{Phase Changes of NaCl-Water Binary Systems}

Sea salt, and in particular its major halide, chloride, is an important reactant in the atmosphere. Chloride in air-borne sea salt aerosol is-once chemically converted to a molecular halogen $\left(\mathrm{Cl}_{2}, \mathrm{BrCl}\right)$ and released to the atmosphere-well known as important atmospheric reactant, driving large-scale changes to the atmospheric composition and in particular to ozone levels in remote areas, but also in coastal mega cities [17, 44]. Similar chemistry has been proposed for sea salt deposits in polar snow covers [45]. A crucial factor determining the overall reactivity is the local physical environment of the chloride ion. For example, the reactivity of liquid aerosols decreases significantly upon crystallization [17, 46, 47]. Surprisingly, the phases of $\mathrm{NaCl}$-containing systems are still under debate [46, 48], partially due to the limited availability of in situ measurements directly probing the local environment at the surface of frozen $\mathrm{NaCl}$-water binary systems. The top panel in Fig. 7 shows the phase diagram of $\mathrm{NaCl}$-water at $200-300 \mathrm{~K}$ in the RH and temperature space as constructed by Koop [49]. Here, the RH parameterizes the concentration of $\mathrm{NaCl}$ in solution, which is used in the more commonly known phase diagrams; the reference at each temperature is the vapor pressure of pure (supercooled) water. The corresponding solution composition can be roughly estimated through Raoult's Law, i.e., the mole fraction of water in the solution identical to $\mathrm{RH}$, or precisely by applying detailed activity based thermodynamic equilibrium models [50], which is significant for the high ionic strength solutions below $80 \% \mathrm{RH}$. The shaded area shows the region where the liquid aqueous solution is thermodynamically stable. The boundaries of this region define the regions at lower temperatures or lower $\mathrm{RH}$ where solids are thermodynamically stable. At the line indicating the ice-solution co-existence, the vapor pressures of ice and of the solution match. The point where the two boundary lines meet is the eutectic where solid ice, solid $\mathrm{NaCl}$ hydrohalite, and aqueous solution are stable and in thermodynamic equilibrium. Below the eutectic temperature of $252 \mathrm{~K}$, the liquid solution of $\mathrm{NaCl}$ in water is thermodynamically not stable as macroscopic solution. It is evident how the water uptake to $\mathrm{NaCl}$ driven by changing $\mathrm{RH}$ dictates the phase of $\mathrm{NaCl}$ and its mixture with ice or water [49]. In particular, the occurrence of the $\mathrm{NaCl}$ hydrohalite has raised some uncertainty [51] as its formation is kinetically hindered. Further, micro-sized 

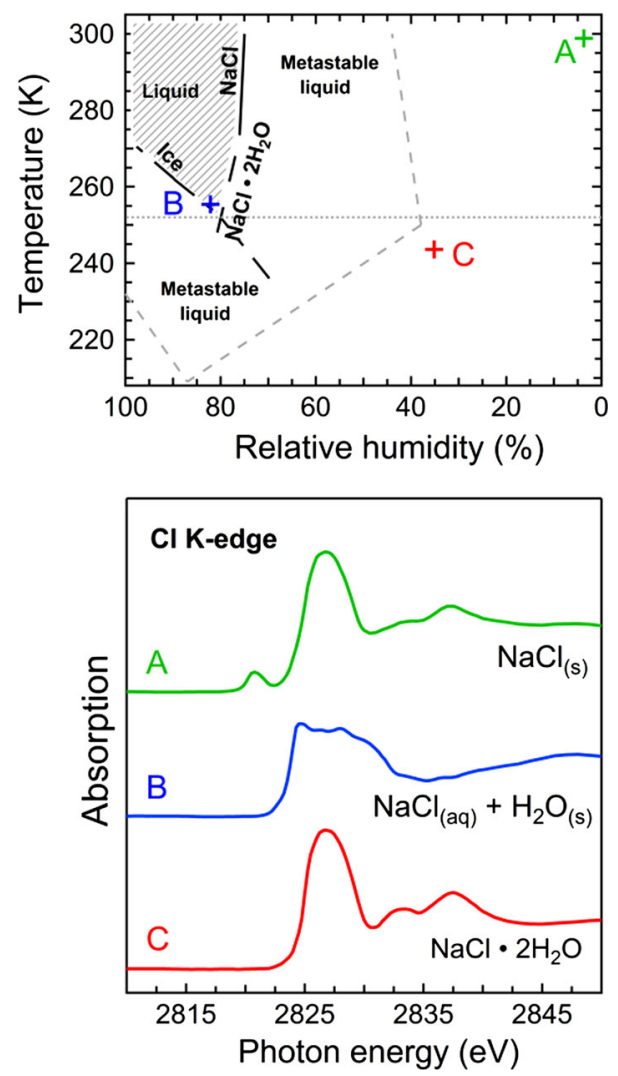

Fig. 7 Top phase diagram of the NaCl-water system [45, 46]; indicated are the measured experimental points. Bottom $\mathrm{Cl}$ K-edge NEXAFS spectra of $(A)$ solid $\mathrm{NaCl}$ at $299 \mathrm{~K}$ and $3 \% \mathrm{RH},(B)$ a binary system of aqueous $\mathrm{NaCl}$ solution-ice at $255 \mathrm{~K}$ and $82 \% \mathrm{RH}$, and $(C) \mathrm{NaCl}$ dihydrate at $243 \mathrm{~K}$ and $35 \% \mathrm{RH}$. The measurements were performed at the PHOENIX beamline

particles have been observed to deviate from this thermodynamic prediction and metastable liquid has been observed in the region indicated by the dashed line in Fig. 7 [49]. In the following, we show how NEXAFS spectroscopy at the $\mathrm{Cl} \mathrm{K}$-edge can be highly informative on the nature of the $\mathrm{NaCl}$ structure in $\mathrm{NaCl}$-water binary systems. Using XPS and NEXAFS spectroscopies of the O 1s core level and $\mathrm{O} \mathrm{K}$-edge, respectively, we previously showed that these systems follow the phase rules at the airice interface [52]. This finding contrasts some earlier observations, where the presence of liquid-like $\mathrm{Cl}$ below the eutectic point of bulk solutions [53] was postulated (see Ref. [46] and references therein). In the present study, by probing the $\mathrm{Cl} \mathrm{K}$-edge, we are sensitive to small changes in the local environment of the chlorine atom and the spectra are not dominated by the excess water molecules as in the case of the $\mathrm{O} \mathrm{K}$-edge spectra reported in our previous investigation. The measurements reported in this section were performed at the PHOENIX beamline at SLS. Auger yield NEXAFS were measured at the $\mathrm{Cl} \mathrm{K}$-edge using a kinetic energy window of $2350-2400 \mathrm{eV}$.
The points at which XPS and Auger yield NEXAFS measurements have been performed are indicated by colored letters in the top panel in Fig. 7. After drying some droplets of $\mathrm{NaCl}$ solution on the sample holder at room temperature, and transferring it into the in situ cell, the solid $\mathrm{NaCl}$ sample was measured at 1.05 mbar water vapor pressure and $299 \mathrm{~K}$ (point (A), RH $3 \%$ ). Next, we increased the water vapor pressure to $2.01 \mathrm{mbar}$ and lowered the temperature to $260 \mathrm{~K}(\mathrm{RH} \sim 107 \%)$ to form a $\mathrm{NaCl}$ solution. At this point, after formation of the solution and its dilution by the excess water vapor pressure provided, we observed sudden nucleation of ice, both optically via the endoscope camera, as well as by a pressure drop in the in situ cell to 1.87 mbar, which is the vapor pressure of ice at the temperature of the frozen sample of $260 \mathrm{~K}$. The formation of ice leads to the formation of a frozen $\mathrm{NaCl}$ solution, i.e. solid ice and liquid $\mathrm{NaCl}$ solution in a 2-phase system. We then equilibrated the system at $255 \mathrm{~K}$ (point (B), 1.17 mbar, $\mathrm{RH} \sim 82 \%$ ). Also this point is above the eutectic temperature of $252 \mathrm{~K}$, meaning that the sample was expected to consist of a mixture of solid ice and of concentrated brine, the water activity of which was equal to the vapor pressure of ice at this temperature. We take advantage of this fundamental principle and derive surface temperatures of frozen aqueous samples based on the measured water vapor pressure in the in situ cell and the parameterization of water vapor pressure over ice by Ref. [54] when working with the cooled sample holder. In the final step, pressure and temperature were set to $0.18 \mathrm{mbar}$ and $243 \mathrm{~K}$, respectively, (point $(\mathrm{C}), \mathrm{RH} \sim 35 \%$ ) in order to slowly evaporate the ice and allow the formation of $\mathrm{NaCl}$ dihydrate $\left(\mathrm{NaCl} \cdot 2 \mathrm{H}_{2} \mathrm{O}\right)$. Note that $\mathrm{NaCl} \cdot 2 \mathrm{H}_{2} \mathrm{O}$ can only be formed in this way, and not by exposing $\mathrm{NaCl}$ to $\mathrm{H}_{2} \mathrm{O}$ [45]. The bottom panel in Fig. 7 shows the chlorine $\mathrm{K}$-edge spectra measured at the above described three points in the $\mathrm{NaCl}$-water phase diagram. Dry $\mathrm{NaCl}$, spectrum (A), shows a main absorption peak at $2825.0 \mathrm{eV}$, corresponding to the transition from $1 \mathrm{~s}$ to $4 \mathrm{p}$ orbitals [55], and a typical post-edge feature [56] at $2836.0 \mathrm{eV}$. The preedge peak at $2820.8 \mathrm{eV}$ can be attributed to $\mathrm{C}-\mathrm{Cl}$ bonds [57] due to carbon contamination of the sample, as sizeable amounts of $\mathrm{NaOCl}$, showing an absorption peak at a similar photon energy [58], can be excluded. The NEXAFS spectrum of the frozen $\mathrm{NaCl}$ solution (B) is quite different compared to that of the solid phase being characterized by a broader edge with two components. The overall shape of this spectrum is in agreement with that reported in Ref. [56] and [59] for aqueous $\mathrm{Cl}^{-}$. Finally, spectrum (C) from the presumed $\mathrm{NaCl}$ dihydrate is almost similar to that of the dry sample, but the carbon-related peak is absent. This can be related to a reduced carbon contamination, as also observed in the associated XPS spectra (not shown here). 
In summary, the $\mathrm{Cl}$ K-edge NEXAFS measurements indicate the formation of a solution above the eutectic, and formation of a solid salt phase below the eutectic and under dryer conditions. More detailed analysis is needed to unequivocally assign the $\mathrm{Cl}$ K-edge NEXAFS to the dihydrate phase of $\mathrm{NaCl}$. These results represent the starting point for an improved understanding of the structure of eutectic and sub-eutectic frozen salt solutions in presence of ice (high relative humidity), and in the hydrate stability domain of the phase diagram (low relative humidity). Moreover, the $\mathrm{Cl} \mathrm{K}$-edge measurements complement and extend previously reported measurements at the O K-edge NEXAFS for the same system [52], which is sensitive to the hydrogen bonding environment of the water molecules. However, compared to the oxygen K-edge, the higher kinetic energy of the chlorine K-edge Auger electron corresponds to an increased probing depth of about 2-8 nm, and, therefore, to a much more bulk-sensitive measurement. This allows for better comparison with other bulk sensitive methods such as those described by Cho et al. [60], who used nuclear magnetic resonance to identify sub-eutectic liquid $\mathrm{NaCl}$.

\subsection{Uptake of Trace Gases to Ice}

In this last example we discuss the adsorption of trace gases to ice, a question of paramount importance in atmospheric and cryospheric environmental science. Another pioneering application of NAPP was the confirmation of the uptake of trace gases to ice, namely acetone [61] and acetic acid [32], which is a relevant process for environmental science, but directly linked also to catalytic research. Core level spectroscopy has successfully shown that strong acids are predominately ionized on amorphous solid water at $90 \mathrm{~K}$ leading to the suggestion of primal dissociation on ice at temperatures relevant to the Earth's environment $[62,63]$. The only study that directly observed the degree of protonation and the structure of the hydrogenbonding network at low dosage at the ice surface at temperatures of $240 \mathrm{~K}$ was recently published by our group [51]. The use of NAPP is particular appealing when targeting high environmental relevance, because this requires operation with temperatures of the ice sample above $\sim 200-240 \mathrm{~K}$. At colder temperatures, the ice structure might deviate from the hexagonal crystal structure typical for the Earth's cryosphere and those samples would thus not mimic environmental ices as ideally [64, 65].

In the following we describe the typical procedure that we followed to grow ice samples in our experiments on formic acid uptake. A constant water vapor pressure of $7.7 \times 10^{-2}$ mbar was established in the analysis cell, which corresponds to an equilibrium vapor pressure of water over ice at $229 \mathrm{~K}$. Then, the temperature of the cooled sample holder was lowered to $218 \mathrm{~K}$ and ice started to grow directly on the copper surface. The water vapor pressure dropped to $2.2 \times 10^{-2}$ mbar because, in presence of ice on the cold sample holder, the vapor pressure of the ice sample at the given temperature determines the water vapor pressure in the analysis cell. As long as this equilibrium vapor pressure was lower than the $7.7 \times 10^{-2}$ mbar dosed to the analysis cell, the ice film grew. After $45 \mathrm{~min}$ the temperature of the cooled sample holder was raised to $229 \mathrm{~K}$ to stop the growth of the ice film and to maintain it stable at equilibrium. Based on calculated flows into the analysis cell and a surface area of the ice film of $0.8 \mathrm{~cm}^{2}$, a thickness of the ice film of $50 \mu \mathrm{m}$ can be estimated. The ice film was allowed to crystallize at a water partial pressure of $4.2 \times 10^{-2} \operatorname{mbar}(223 \mathrm{~K})$ for $12 \mathrm{~h}$ prior to the formic acid dosing. This pressure is slightly lower than the vapor pressure of $7.7 \times 10^{-2}$ mbar in absence of ice and corresponds to a slightly growing ice regime. Within this regime, the intensity of the $\mathrm{O}$ 1s XPS spectra did not change with time, thus indicating that the ice film at the measurement spot was stable. The slightly growing ice regime indicated by the macroscopic pressure measurements might be attributed to a heterogeneous temperature distribution at the sample holder, or might indicate that this growth compensated the evaporation of ice caused either by heat transfer from the beam or by the pressure field gradient in the proximity of the aperture cone of the analyzer. Once a stable condition for the ice film was established, the formic acid was dosed into the chamber. Figure 8 shows an example of XPS survey spectrum of a clean ice surface showing the $\mathrm{O} 1 \mathrm{~s}, 2 \mathrm{~s}$ and $2 \mathrm{p}$ peaks at 533, 25 and about $7 \mathrm{eV}$, and the $\mathrm{O}$ Auger region. This spectrum was measured at the SIM beamline using a photon energy of $730 \mathrm{eV}$.

Figure 9 shows the $\mathrm{C}$ 1s spectra measured during the formic acid uptake at the ice surface. $\mathrm{C} 1 \mathrm{~s}$ and $\mathrm{O} 1 \mathrm{~s}$ core levels (the latter not shown here) were measured in

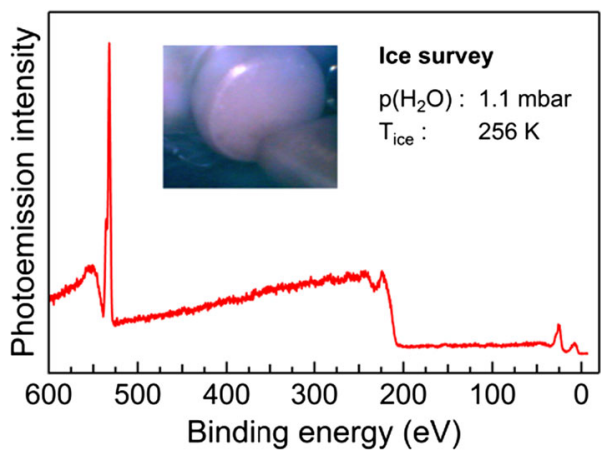

Fig. 8 Survey spectrum of the ice surface taken at the SIM beamline of PSI/SLS with a photon energy of $730 \mathrm{eV}$. Note the absence of carbon, nitrogen, or other contamination traces. The inset shows a picture of the polycrystalline, crystal-clear ice film on the cooled sample holder and of the electron analyzer cone in measurement position taken during the measurement 


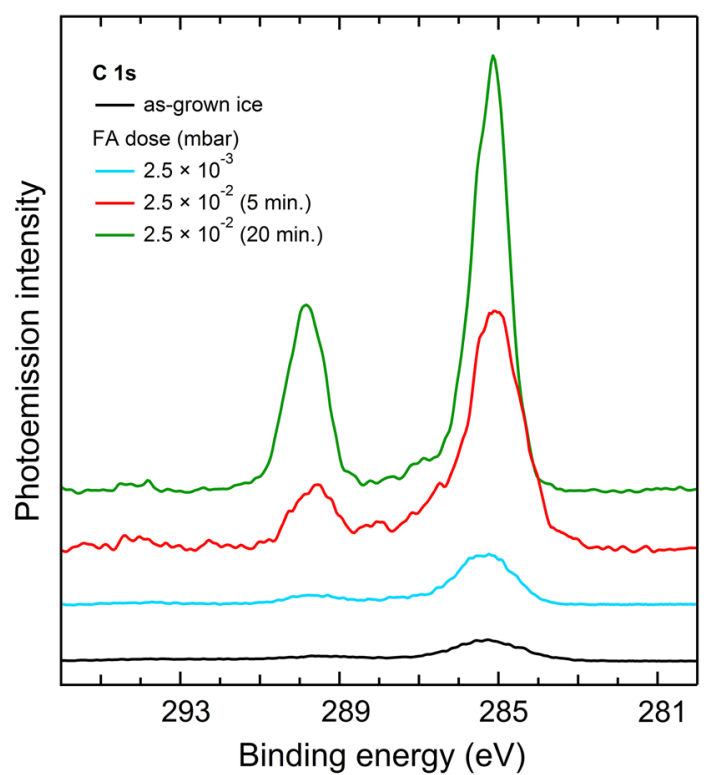

Fig. $9 \mathrm{C}$ 1s core level spectra measured during formic acid uptake on the ice surface at $223 \mathrm{~K}$ and $4.2 \times 10^{-2}$ mbar partial water vapor pressure in the analysis cell. The measurements were performed at the PHOENIX beamline of PSI/SLS with a photon energy of $2200 \mathrm{eV}$. The C 1s spectra are vertically shifted for display

sequence during the uptake at the PHOENIX beamline using a photon energy of $2200 \mathrm{eV}$. The $\mathrm{C} 1 \mathrm{~s}$ spectra are referenced to the binding energy of the $\mathrm{O} 1 \mathrm{~s}$ core level peak

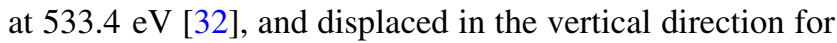
clarity. The $\mathrm{C} 1 \mathrm{~s}$ spectrum measured before the admission of formic acid into the analysis cell (black spectrum) shows a component at about $285 \mathrm{eV}$ that is associated to adventitious carbon contamination. Carbon impurities might desorb from the wall surfaces of the flow tube cell in the high pressure regime, for instance, during the ice growth. In addition, beam-induced photochemistry and/or contamination of the formic acid source may further contribute to this component, as its intensity increased during formic acid uptake. Once a formic acid partial pressure of $2.5 \times 10^{-3}$ mbar was established in the analysis cell, the adventitious carbon peak slightly grew, and a broad feature appeared at about $290 \mathrm{eV}$, which is representative of carbon in a $-\mathrm{C}(\mathrm{O}) \mathrm{OH}$ (carboxyl) functional group. After increasing the partial pressure to $2.5 \times 10^{-2} \mathrm{mbar}$, a direct response of the $-\mathrm{C}(\mathrm{O}) \mathrm{OH}$ intensity to the dosing of formic acid is evident. Within 5 min of dosing the $-\mathrm{C}(\mathrm{O}) \mathrm{OH}$ signal increased significantly (red spectrum) and after $20 \mathrm{~min}$, when the uptake and pressure equilibrium at the sample was reached, a very intense and sharp peak had evolved (green spectrum). At this point, the visual inspection of the ice surface revealed a marked change of the sample, and its shiny look indicated the onset of melting. At this partial pressure range of about
$2.5 \times 10^{-2}$ mbar, the formic acid lowers the melting point of ice so that melting at $223 \mathrm{~K}$ might have occurred. This is based on a back-of-the envelope calculation of the ice melting point depression of formic acid [66] using Raoult's law. It is important to note that the response to changes in pressure illustrated in Figs. 9 and 3 represents a great improvement compared to the very long equilibration time, typically several hours, required for acid trace gases uptake with standard NAPP setups at comparable partial pressures [32]. Moreover, it is noteworthy that this is the first direct observation of formic acid on ice, as earlier studies were based on indirect observations of the gas-phase concentration of formic acid upon contact with ice samples [67, 68]. It is planned to continue the investigation of formic acid adsorbed to ice in the future.

\section{Summary and Conclusions}

A new chamber for near ambient pressure XPS and NEXAFS investigation of solid/vapor interfaces at the NAPP endstation has been presented. We have described first results on the photochemistry of $\mathrm{TiO}_{2}$ that support previous experimental findings about increased concentration of water on $\mathrm{TiO}_{2}$ under humid conditions and UV irradiation. Furthermore, we have characterized several distinct points in the $\mathrm{NaCl}-\mathrm{H}_{2} \mathrm{O}$ phase diagram via NEXAFS spectroscopy measurements at the $\mathrm{Cl} \mathrm{K}$-edge and correlated them with observed phase transitions. Finally, in the last example we have proved the feasibility of ice samples growth with the new chamber and the possibility, precluded with other standard NAPP setups, to investigate the interaction of this and other surfaces with sticky acidic gases with reasonable equilibration times. These examples demonstrate the capability to study interfaces between solids and vapors as well as aqueous solutions, thus proving the potential of this new chamber at NAPP endstation for the investigation of many scientific cases of relevance to environmental and atmospheric chemistry.

Acknowledgments Swiss National Science Foundation (SNF R'Equip, Grant No. 139139, SNF Grant Nos. 149492, 149629), PSI FoKo, SLS QV program, and the Center of Competence in Energy and Mobility (CCEM, NADiP project). Part of the work has been performed at the Surface/Interface: Microscopy (SIM) and PHOENIX beamlines at the Swiss Light Source.

Open Access This article is distributed under the terms of the Creative Commons Attribution 4.0 International License (http://crea tivecommons.org/licenses/by/4.0/), which permits unrestricted use, distribution, and reproduction in any medium, provided you give appropriate credit to the original author(s) and the source, provide a link to the Creative Commons license, and indicate if changes were made. 


\section{References}

1. Siegbahn H, Siegbahn K (1973) ESCA applied to liquids. J Electron Spectrosc Relat Phenom 2:319-325

2. Joyner RW, Roberts MW, Yates K (1979) A "high-pressure" electron spectrometer for surface studies. Surf Sci 87:501-509

3. Ruppender HJ, Grunze M, Kong CW, Wilmers M (1990) In situ X-ray photoelectron spectroscopy of surfaces at pressures up to 1 mbar. Surf Interface Anal 15:245-253

4. Ogletree DF, Bluhm H, Lebedev G, Fadley CS, Hussain Z, Salmeron $M$ (2002) A differentially pumped electrostatic lens system for photoemission studies in the millibar range. Rev Sci Instrum 73:3872

5. Bluhm H, Hävecker M, Knop-Gericke A, Kleimenov E, Schlbögl R, Teschner D, Bukhtiyarov VI, Ogletree DF, Salmeron M (2004) Methanol oxidation on a copper catalyst investigated using in situ X-ray photoelectron spectroscopy. J Phys Chem B 108: 14340-14347

6. Frank Ogletree D, Bluhm H, Hebenstreit ED, Salmeron M (2009) Photoelectron spectroscopy under ambient pressure and temperature conditions. Nuclear Instruments and Methods in Physics Research Section A: accelerators, Spectrometers, Detectors and Associated Equipment 601:151-160

7. Grass ME, Karlsson PG, Aksoy F, Lundqvist M, Wannberg B, Mun BS, Hussain Z, Liu Z (2010) New ambient pressure photoemission endstation at Advanced Light Source beamline 9.3.2. Rev Sci Instrum 81:053106

8. Schnadt J, Knudsen J, Andersen JN, Siegbahn H, Pietzsch A, Hennies F, Johansson N, Martensson N, Ohrwall G, Bahr S, Mahl S, Schaff O (2012) The new ambient-pressure X-ray photoelectron spectroscopy instrument at MAX-lab. J Synchrotron Radiat 19:701-704

9. Pérez-Dieste V, Aballe L, Ferrer S, Nicolàs J, Escudero C, Milán A, Pellegrin E (2013) Near ambient pressure XPS at ALBA. J Phys 425:072023

10. Kaya S, Ogasawara H, Näslund L- $\AA$, Forsell J-O, Casalongue HS, Miller DJ, Nilsson A (2013) Ambient-pressure photoelectron spectroscopy for heterogeneous catalysis and electrochemistry. Catal Today 205:101-105

11. Toyoshima R, Kondoh H (2015) In-situ observations of catalytic surface reactions with soft $\mathrm{x}$-rays under working conditions. J Phys Condens Matter 27:083003

12. Liu X, Yang W, Liu Z (2014) Recent progress on synchrotronbased in situ soft X-ray spectroscopy for energy materials. Adv Mater 26:7710-7729

13. Salmeron M, Schlögl R (2008) Ambient pressure photoelectron spectroscopy: a new tool for surface science and nanotechnology. Surf Sci Rep 63:169-199

14. Ghosal S, Hemminger JC, Bluhm H, Mun BS, Hebenstreit ELD, Ketteler G, Ogletree DF, Requejo FG, Salmeron M (2005) Electron spectroscopy of aqueous solution interfaces reveals surface enhancement of halides. Science 307:563-566

15. Carrasco J, Hodgson A, Michaelides A (2012) A molecular perspective of water at metal interfaces. Nat Mater 11:667-674

16. Bluhm H (2010) Photoelectron spectroscopy of surfaces under humid conditions. J Electron Spectrosc Relat Phenom 177:71-84

17. Abbatt JPD, Thomas JL, Abrahamsson K, Boxe C, Granfors A, Jones AE, King MD, Saiz-Lopez A, Shepson PB, Sodeau J, Toohey DW, Toubin C, von Glasow R, Wren SN, Yang X (2012) Halogen activation via interactions with environmental ice and snow in the polar lower troposphere and other regions. Atmos Chem Phys 12:6237-6271

18. Bartels-Rausch T, Jacobi H-W, Kahan TF, Thomas JL, Thomson ES, Abbatt JPD, Ammann M, Blackford JR, Bluhm H, Boxe C, Dominé F, Frey MM, Gladich I, Guzman MI, Heger D,
Huthwelker T, Klán P, Kuhs WF, Kuo MH, Maus S, Moussa SG, McNeill VF, Newberg JT, Pettersson JBC, Roeselova M, Sodeau JR (2014) A review of air-ice chemical and physical interactions (AICI): liquids, quasi-liquids, and solids in snow. Atmos Chem Phys 14:1587-1633

19. McNeill VF, Dominé F, Grannas AM, Abbatt JPD, Ammann M, Ariya PA, Bartels-Rausch T, Donaldson DJ, Guzman MI, Heger D, Kahan TF, Klán P, Masclin S, Toubin C, Voisin D (2012) Organics in environmental ices: sources, chemistry, and impacts. Atmos Chem Phys 12:9653-9678

20. George C, D'Anna B, Herrmann H, Weller C, Vaida V, Donaldson DJ, Bartels-Rausch T, Ammann M (2012) Emerging areas in atmospheric photochemistry. Springer, Berlin, pp 1-54

21. Grannas AM, Jones AE, Dibb J, Ammann M, Anastasio C, Beine HJ, Bergin M, Bottenheim J, Boxe CS, Carver G, Chen G, Crawford JH, Domine F, Frey MM, Guzman MI, Heard DE, Helmig D, Hoffmann MR, Honrath RE, Huey LG, Hutterli M, Jacobi HW, Klan P, Lefer B, McConnell J, Plane J, Sander R, Savarino J, Shepson PB, Simpson WR, Sodeau JR, von Glasow R, Weller R, Wolff EW, Zhu T (2007) An overview of snow photochemistry: evidence, mechanisms and impacts. Atmos Chem Phys 7:4329-4373

22. Pratt KA, Custard KD, Shepson PB, Douglas TA, Pöhler D, General S, Zielcke J, Simpson WR, Platt U, Tanner DJ, Gregory Huey L, Carlsen M, Stirm BH (2013) Photochemical production of molecular bromine in Arctic surface snowpacks. Nat Geosci 6:351-356

23. Simpson W, von Glasow R, Anderson P, Anderson P, Ariya PA, Bottenheim JW, Burrows J, Carpenter L, Carpenter L, Friess U, Goodsite M, Heard D, Heard D, Hutterli MA, Jacobi H-W, Kaleschke L, Plane J, Plane J, Platt U, Richter A, Roscoe H, Sander R, Shepson PB, Sodeau JR, Steffen A, Wolff EW (2007) Halogens and their role in polar boundary-layer ozone depletion. Atmos Chem Phys 7:4375-4418

24. Bluhm H, Ogletree DF, Fadley CS, Hussain Z, Salmeron M (2002) The premelting of ice studied with photoelectron spectroscopy. J Phys 14:L227-L233

25. Lampimäki M, Schreiber S, Zelenay V, Křepelová A, Birrer M, Axnanda S, Mao B, Liu Z, Bluhm H, Ammann M (2015) Exploring the environmental photochemistry on the $\mathrm{TiO}_{2}(110)$ surface in situ by near ambient pressure X-ray photoelectron spectroscopy. J Phys Chem C 119:7076

26. Rosseler O, Sleiman M, Montesinos VN, Shavorskiy A, Keller V, Keller N, Litter MI, Bluhm H, Salmeron M, Destaillats H (2013) Chemistry of $\mathrm{NO}_{\mathrm{x}}$ on $\mathrm{TiO}_{2}$ surfaces studied by ambient pressure XPS: products, effect of UV irradiation, water, and coadsorbed K+. J Phys Chem Lett 4:536-541

27. Brown MA, Redondo AB, Jordan I, Duyckaerts N, Lee M-T, Ammann M, Nolting F, Kleibert A, Huthwelker T, Mächler J-P, Birrer M, Honegger J, Wetter R, Wörner HJ, van Bokhoven JA (2013) A new endstation at the Swiss Light Source for ultraviolet photoelectron spectroscopy, and X-ray photoelectron spectroscopy, and X-ray absorption spectroscopy measurements of liquid solutions. Rev Sci Instrum 84:073904

28. Flechsig U, Nolting F, Fraile Rodríguez A, Krempaský J, Quitmann C, Schmidt T, Spielmann S, Zimoch D (2010) Performance measurements at the SLS SIM beamline. AIP Conf Proc 1234:319-322

29. Kato S, Ammann M, Huthwelker T, Paun C, Lampimaki M, Lee M-T, Rothensteiner M, van Bokhoven JA (2015) Quantitative depth profiling of $\mathrm{Ce}_{3+}$ in $\mathrm{Pt} / \mathrm{CeO}_{2}$ by in situ high-energy XPS in a hydrogen atmosphere. Phys Chem Chem Phys 17:5078-5083

30. Eriksson SK, Hahlin M, Kahk JM, Villar-Garcia IJ, Webb MJ, Grennberg H, Yakimova R, Rensmo H, Edström K, Hagfeldt A, Siegbahn H, Edwards MOM, Karlsson PG, Backlund K, Åhlund 
J, Payne DJ (2014) A versatile photoelectron spectrometer for pressures up to 30 mbar. Rev Sci Instrum 85:075119

31. Tao FF (2012) Operando studies of catalyst surfaces during catalysis and under reaction conditions: ambient pressure X-ray photoelectron spectroscopy with a flow-cell reactor. ChemCatChem 4:583-590

32. Křepelová A, Bartels-Rausch T, Brown MA, Bluhm H, Ammann M (2012) Adsorption of acetic acid on ice studied by ambientpressure XPS and partial-electron-yield NEXAFS spectroscopy at 230-240 K. J Phys Chem A 117:401-409

33. Salthammer T, Fuhrmann F (2007) Photocatalytic surface reactions on indoor wall paint. Environ Sci Technol 41:6573-6578

34. Kwon S, Fan M, Cooper AT, Yang H (2008) Photocatalytic applications of micro- and nano- $\mathrm{TiO}_{2}$ in environmental engineering. Crit Rev Environ Sci Technol 38:197-226

35. Chen H, Nanayakkara CE, Grassian VH (2012) Titanium dioxide photocatalysis in atmospheric chemistry. Chem Rev 112: 5919-5948

36. Monge ME, George C, D'Anna B, Doussin JF, Jammoul A, Wang J, Eyglunent G, Solignac G, Daële V, Mellouki A (2010) Ozone formation from illuminated titanium dioxide surfaces. J Am Chem Soc 132:8234-8235

37. Ketteler G, Yamamoto S, Bluhm H, Andersson K, Starr DE, Ogletree DF, Ogasawara H, Nilsson A, Salmeron M (2007) The nature of water nucleation sites on $\mathrm{TiO}_{2}(110)$ surfaces revealed by ambient pressure X-ray photoelectron spectroscopy. J Phys Chem C 111:8278-8282

38. Yamamoto S, Bluhm H, Andersson K, Ketteler G, Ogasawara H, Salmeron M, Nilsson A (2008) In situ x-ray photoelectron spectroscopy studies of water on metals and oxides at ambient conditions. J Phys 20:184025

39. Lampimäki M, Zelenay V, Křepelová A, Liu Z, Chang R, Bluhm H, Ammann M (2013) Ozone-induced band bending on metaloxide surfaces studied under environmental conditions. ChemPhysChem 14:2419-2425

40. Zhang Z, Yates JT (2012) Band bending in semiconductors: chemical and physical consequences at surfaces and interfaces. Chem Rev 112:5520-5551

41. De Groot FMF, Faber J, Michiels JJM, Czyyk MT, Abbate M, Fuggle JC (1993) Oxygen 1s x-ray absorption of tetravalent titanium oxides: a comparison with single-particle calculations. Phys Rev B 48:2074-2080

42. Myneni S, Luo Y, Näslund LÅ, Cavalleri M, Ojamäe L, Ogasawara $\mathrm{H}$, Pelmenschikov A, Wernet $\mathrm{P}$, Väterlein $\mathrm{P}$, Heske C, Hussain Z, Pettersson LGM, Nilsson A (2002) Spectroscopic probing of local hydrogen-bonding structures in liquid water. J Phys 14:L213

43. Wu ZY, Ouvrard G, Gressier P, Natoli CR (1997) Ti and O $K$ edges for titanium oxides by multiple scattering calculations: comparison to XAS and EELS spectra. Phys Rev B 55: 10382-10391

44. Osthoff HD, Roberts JM, Ravishankara AR, Williams EJ, Lerner BM, Sommariva R, Bates TS, Coffman D, Quinn PK, Dibb JE, Stark H, Burkholder JB, Talukdar RK, Meagher J, Fehsenfeld FC, Brown SS (2008) High levels of nitryl chloride in the polluted subtropical marine boundary layer. Nat Geosci 1:324-328

45. Koop T, Kapilashrami A, Molina LT, Molina MJ (2000) Phase transitions of sea-salt/water mixtures at low temperatures: implications for ozone chemistry in the polar marine boundary layer. J Geophys Res 105:26393-26402

46. Bartels-Rausch T, Jacobi HW, Kahan TF, Thomas JL, Thomson ES, Abbatt JPD, Ammann M, Blackford JR, Bluhm H, Boxe C, Domine F, Frey MM, Gladich I, Guzmán MI, Heger D, Huthwelker T, Klán P, Kuhs WF, Kuo MH, Maus S, Moussa SG, McNeill VF, Newberg JT, Pettersson JBC, Roeselová M, Sodeau JR (2014) A review of air-ice chemical and physical interactions
(AICI): liquids, quasi-liquids, and solids in snow. Atmos Chem Phys $14: 1587-1633$

47. Kolb CE, Cox RA, Abbatt JPD, Ammann M, Davis EJ, Donaldson DJ, Garrett BC, George C, Griffiths PT, Hanson DR, Kulmala M, McFiggans G, Pöschl U, Riipinen I, Rossi MJ, Rudich Y, Wagner PE, Winkler PM, Worsnop DR, O'Dowd CD (2010) An overview of current issues in the uptake of atmospheric trace gases by aerosols and clouds. Atmos Chem Phys 10:10561-10605

48. Bruzewicz DA, Checco A, Ocko BM, Lewis ER, McGraw RL, Schwartz SE (2011) Reversible uptake of water on $\mathrm{NaCl}$ nanoparticles at relative humidity below deliquescence point observed by noncontact environmental atomic force microscopy. J Chem Phys 134:044702

49. Koop T, Kapilashrami A, Molina LT, Molina MJ (2000) Phase transitions of sea-salt/water mixtures at low temperatures: implications for ozone chemistry in the polar marine boundary layer. J Geophys Res 105:26393-26326-26393-26402

50. Clegg SL, Brimblecombe P, Wexler AS (1998) Thermodynamic model of the system $\mathrm{H}^{+}-\mathrm{NH}_{4}{ }^{+}-\mathrm{Na}^{+}-\mathrm{SO}_{4}{ }^{2-}-\mathrm{NO}^{3-}-\mathrm{Cl}^{-}-\mathrm{H}_{2} \mathrm{O}$ at 298.15 K. J Phys Chem A 102:2155-2171

51. Huthwelker T, Ammann M, Peter T (2006) The uptake of acidic gases on ice. Chem Rev 106:1375-1444

52. Křepelová A, Huthwelker T, Bluhm H, Ammann M (2010) Surface chemical properties of eutectic and frozen $\mathrm{NaCl}$ solutions probed by XPS and NEXAFS. ChemPhysChem 11:3859-3866

53. Cheng Y, Su H, Koop T, Mikhailov E, Pöschl U (2015) Size dependence of phase transitions in aerosol nanoparticles. Nat Commun 6:5923

54. Marti J, Mauersberger K (1993) A survey and new measurements of ice vapor pressure at temperatures between 170 and $250 \mathrm{~K}$. Geophys Res Lett 20:363-366

55. Evans KA, Mavrogenes JA, O'Neill HS, Keller NS, Jang LY (2008) A preliminary investigation of chlorine XANES in silicate glasses. Geochem Geophys Geosyst 9:Q10003

56. Huggins FE, Huffman GP (1995) Chlorine in coal: an XAFS spectroscopic investigation. Fuel 74:556-569

57. Fujimori T, Takaoka M, Morisawa S (2010) Chlorinated aromatic compounds in a thermal process promoted by oxychlorination of ferric chloride. Environ Sci Technol 44:1974-1979

58. Vaudey CE, Gaillard C, Toulhoat N, Moncoffre N, Schlegel ML, Raimbault L (2011) Chlorine speciation in nuclear graphite studied by X-ray absorption near edge structure. J Nucl Mater 418:16-21

59. Leri AC, Marcus MA, Myneni SCB (2007) X-ray spectromicroscopic investigation of natural organochlorine distribution in weathering plant material. Geochim Cosmochim Acta 71: 5834-5846

60. Cho H, Shepson PB, Barrie LA, Cowin JP, Zaveri R (2002) NMR investigation of the quasi-brine layer in ice/brine mixtures. J Phys Chem B 106:11226-11232

61. Starr DE, Pan D, Newberg JT, Ammann M, Wang EG, Michaelides A, Bluhm H (2011) Acetone adsorption on ice investigated by X-ray spectroscopy and density functional theory. Phys Chem Chem Phys 13:19988-19996

62. Marcotte G, Ayotte P, Bendounan A, Sirotti F, Laffon C, Parent P (2013) Dissociative adsorption of nitric acid at the surface of amorphous solid water revealed by X-ray absorption spectroscopy. J Phys Chem Lett 4:2643-2648

63. Parent P, Lasne J, Marcotte G, Laffon C (2011) HCl adsorption on ice at low temperature: a combined X-ray absorption, photoemission and infrared study. Phys Chem Chem Phys 13: 7142-7148

64. Bartels-Rausch T, Bergeron V, Cartwright J, Escribano R, Finney J, Grothe H, Gutiérrez P, Haapala J, Kuhs WF, Pettersson J, Price S, Sainz-Díaz C, Stokes D, Strazzulla G, Thomson ES, Trinks H, 
Uras-Aytemiz N (2012) Ice structures, patterns, and processes: a view across the icefields. Rev Mod Phys 84:885-944

65. Kuhs WF, Sippel C, Falenty A, Hansen TC (2012) Extent and relevance of stacking disorder in in "ice I(c)". Proc Natl Acad Sci 109:21259-21264

66. J. Timmermans, Physico-chemical constants of binary systems in concentrated solutions - systems with inorganic + organic or inorganic compounds (excepting metallic derivatives), Knovel
67. Jedlovszky P, Hantal G, Neuróhr K, Picaud S, Hoang PNM, Von Hessberg P, Crowley JN (2008) Adsorption isotherm of formic acid on the surface of ice, as seen from experiments and grand canonical Monte Carlo simulation. J Phys Chem C 112:8976-8987

68. Von Hessberg P, Pouvesle N, Winkler AK, Schuster G, Crowley JN (2008) Interaction of formic and acetic acid with ice surfaces between 187 and $227 \mathrm{~K}$. Investigation of single species- and competitive adsorption. Phys Chem Chem Phys 10:2345-2355 